\title{
Unawareness of hypoglycaemia and inadequate hypoglycaemic counterregulation: no causal relation with diabetic autonomic neuropathy
}

\author{
R E J Ryder, D R Owens, T M Hayes, M A Ghatei, S R Bloom
}

\section{Abstract}

Objective-To examine the traditional view that unawareness of hypoglycaemia and inadequate hypoglycaemic counterregulation in insulin dependent diabetes mellitus are manifestations of autonomic neuropathy.

Design-Perspective assessment of unawareness of hypoglycaemia and detailed assessment of autonomic neuropathy in patients with insulin dependent diabetes according to the adequacy of their hypoglycaemic counterregulation.

Setting-One routine diabetic unit in a university teaching hospital.

Patients-23 Patients aged 21-52 with insulin dependent diabetes mellitus (seven with symptoms suggesting autonomic neuropathy, nine with a serious clinical problem with hypoglycaemia, and seven without symptoms of autonomic neuropathy and without problems with hypoglycaemia) and 10 controls with a similar age distribution, without a personal or family history of diabetes.

Main outcome measures-Presence of autonomic neuropathy as assessed with a test of the longest sympathetic fibres (acetylcholine sweatspot test), a pupil test, and a battery of seven cardiovascular autonomic function tests; adequacy of hypoglycaemic glucose counterregulation during a $40 \mathrm{mU} / \mathrm{kg} / \mathrm{h}$ insulin infusion test; history of unawareness of hypoglycaemia; and response of plasma pancreatic polypeptide during hypoglycaemia, which depends on an intact and responding autonomic innervation of the pancreas.

Results-There was little evidence of autonomic neuropathy in either the 12 diabetic patients with a history of unawareness of hypoglycaemia or the seven patients with inadequate hypoglycaemic counterregulation. By contrast, in all seven patients with clear evidence of autonomic neuropathy there was no history of unawareness of hypoglycaemia and in six out of seven there was adequate hypoglycaemic counterregulation. Unawareness of hypoglycaemia and inadequate hypoglycaemic counterregulation were significantly associated $(\mathbf{p}<\mathbf{0 . 0 1})$. The response of plasma pancreatic polypeptide in the diabetic patients with adequate counterregulation but without autonomic neuropathy was not significantly different from that of the controls (change in plasma pancreatic polypeptide $226.8 v 414 \mathrm{pmol} / \mathrm{l})$. The patients with autonomic neuropathy had a negligible plasma pancreatic polypeptide response $(3.7 \mathrm{pmol} / \mathrm{l})$, but this response was also blunted in the patients with inadequate hypoglycaemic counterregulation $(72.4 \mathrm{pmol} / \mathrm{l})$ compared with that of the controls $(p<0.05)$.

Conclusions-Unawareness of hypoglycaemia and inadequate glucose counterregulation during hypoglycaemia are related to each other but are not due to autonomic neuropathy. The blunted plasma pancreatic polypeptide responses of the patients with inadequate hypoglycaemic counterregulation may reflect diminished autonomic activity consequent upon reduced responsiveness of a central glucoregulatory centre, rather than classical autonomic neuropathy.

\section{Introduction}

Unawareness of hypoglycaemia in diabetic patients is, by tradition, ascribed to autonomic neuropathy..$^{1-3}$ Some patients with insulin dependent diabetes mellitus have been shown to produce inadequate amounts of adrenaline and glucagon in response to hypoglycaemia, and these patients are more at risk from neuroglycopenia and hypoglycaemic coma. ${ }^{4}$ Diabetic autonomic neuropathy has also been suggested as the cause of defective adrenaline secretion in these patients, ${ }^{47}$ and, in this way, as the cause of inadequate counterregulation. Previous studies investigating diabetic autonomic neuropathy and inadequate counterregulation have included only limited assessment of autonomic function, giving rise to conflicting results. ${ }^{89}$ We used an extensive battery of investigations of autonomic neuropathy to re-examine the relations among autonomic neuropathy, hypogly caemic unawareness, and inadequate hypoglycaemic counterregulation.

\section{Patients and methods} PATIENTS

If problems with hypoglycaemia are due to autonomic neuropathy patients with autonomic neuropathy would be expected to show evidence of such problems and, conversely, patients with such problems would be expected to show evidence of autonomic neuropathy. Thus our aims were to identify patients with unawareness of hypoglycaemia and inadequate hypoglycaemic counterregulation and assess them in detail for autonomic neuropathy and to identify patients with autonomic neuropathy and assess them for problems with hypoglycaemia. To facilitate identification of such patients, subjects dependent on insulin, recruited randomly from the routine hospital diabetic clinic, were invited to take part in the study if they fitted into one of three groups: group 1 , with symptoms suggesting autonomic neuropathy (postural hypotension, gustatory sweating, gastroparesis, oesophageal atony, diarrhoea, neurogenic bladder, impotence, unexplained ankle oedema ${ }^{2}$ ); group 2, with a serious clinical problem with hypoglycaemia; group 3 , without symptoms suggesting autonomic neuropathy and without a problem with hypoglycaemia. In total, 23 patients with insulin dependent diabetes mellitus were studied (seven in group 1, nine in group 2 , and seven in 
group 3). Table I shows their clinical characteristics. Ten controls of similar age distribution to the diabetic patients and with no personal or family history of diabetes were also studied.

\section{METHODS}

Samples of blood were taken for determination of haemoglobin $A_{1}$ and creatinine concentrations. Diabetic retinopathy was assessed by non-mydriatic retinal photography ${ }^{10}$ and ophthalmoscopy. $\beta$ Cell function was assessed by the $C$ peptide response to intravenous glucagon. ${ }^{11}$ All patients were asked whether they always had warning of hypoglycaemia, sometimes had no warning, or often had no warning; they then had an extensive autonomic assessment and an insulin infusion test for adequacy of hypoglycaemic glucose counterregulation with measurement of pancreatic polypeptide response during that test.

Assessment of autonomic neuropathy-On the grounds that diabetic autonomic neuropathy is a symmetrical polyneuropathy that affects the longest fibres first, ${ }^{212}$ we used a recently developed test (acetylcholine sweatspot test) for autonomic denervation in the longest sympathetic fibres. ${ }^{13}$ Acetylcholine was given intradermally into a standard site on the dorsum of the foot, which had previously been painted with starch and iodine. This causes spots of discoloration of the iodine at the sites of innervated sweat glands. Areas of denervation (without spots) were measured by photographing the response and scoring the photograph using a grid (normal $=0$ or 1 ; abnormal $=5-60$.) The sweatspot test was backed up by a battery of seven cardiovascular autonomic function tests performed with a computer assisted system (R-R Medical Electronics, Leeds): (a) variation in heart rate during deep breathing ${ }^{14} ;(b)$ Valsalva manoeuvre ${ }^{14} ;(c)$ diastolic blood pressure response to sustained hand grip ${ }^{14}$ (d) standard deviation of the electrocardiographic R-R interval during quiet standing ${ }^{15} ;(e)$ acceleration index ${ }^{16}$ based on heart rate (rather than the $R-R$ interval) during upright tilt; $(f)$ brake index ${ }^{16}$ based on heart rate during upright tilt; and $(g)$ fall in systolic blood pressure after upright tilt. ${ }^{16}$ Reference ranges for tests a-c were those of Ewing and Clarke ${ }^{14}$; for tests d-g age related reference ranges were established in 50 normal volunteers aged 20-69. Patients also were given a

TABLE I-Clinical details of three groups of diabetic patients studied

\begin{tabular}{|c|c|c|c|c|c|c|}
\hline Case No & $\begin{array}{l}\text { Age } \\
(\text { sex })\end{array}$ & $\begin{array}{c}\text { Body mass index } \\
\left(\mathrm{kg} / \mathrm{m}^{2}\right)\end{array}$ & $\begin{array}{c}\begin{array}{c}\text { Duration of } \\
\text { diabetes } \\
\text { (years) }\end{array} \\
\end{array}$ & $\mathrm{HbA}_{1}(\%)$ & Retinopathy & $\begin{array}{c}\text { Hypoglycaemic } \\
\text { counterregulation }\end{array}$ \\
\hline \multicolumn{7}{|c|}{ Group $1(n=7)$} \\
\hline $\begin{array}{l}1 \\
2 \\
3 \\
4 \\
5 \\
6 \\
7\end{array}$ & $\begin{array}{l}25(\mathrm{~F}) \\
35(\mathrm{M}) \\
41(\mathrm{~F}) \\
46(M) \\
52(\mathrm{M}) \\
26(\mathrm{M}) \\
50(\mathrm{M})\end{array}$ & $\begin{array}{l}15 \cdot 55 \\
24 \cdot 51 \\
18 \cdot 17 \\
22 \cdot 22 \\
24 \cdot 60 \\
28 \cdot 39 \\
25 \cdot 68\end{array}$ & $\begin{array}{r}18 \\
19 \\
32 \\
12 \\
22 \\
4 \\
25\end{array}$ & $\begin{array}{r}12.4 \\
17.5 \\
11.5 \\
9.8 \\
9.7 \\
8.7 \\
11.4\end{array}$ & $\begin{array}{c}4 \\
2 \\
3 \\
4 \\
3,6 \\
1 \\
6\end{array}$ & $\begin{array}{l}\text { Borderline } \\
\text { Adequate } \\
\text { Adequate } \\
\text { Adequate } \\
\text { Adequate } \\
\text { Adequate } \\
\text { Adequate }\end{array}$ \\
\hline \multicolumn{7}{|c|}{ Group $2(n=9)$} \\
\hline $\begin{array}{r}8 \\
9 \\
10 \\
11 \\
12 \\
13 \\
14 \\
15 \\
16\end{array}$ & $\begin{array}{l}34(\mathrm{~F}) \\
48(\mathrm{M}) \\
36(\mathrm{M}) \\
30(\mathrm{~F}) \\
44(\mathrm{~F}) \\
31(\mathrm{~F}) \\
30(\mathrm{~F}) \\
37(\mathrm{M}) \\
27(\mathrm{M})\end{array}$ & $\begin{array}{l}26 \cdot 42 \\
23 \cdot 64 \\
26 \cdot 67 \\
24 \cdot 40 \\
21 \cdot 31 \\
23 \cdot 74 \\
22 \cdot 54 \\
21 \cdot 54 \\
24 \cdot 11\end{array}$ & $\begin{array}{r}22 \\
16 \\
6 \\
10 \\
18 \\
12 \\
7 \\
14 \\
9\end{array}$ & $\begin{array}{r}9 \cdot 5 \\
9 \cdot 8 \\
10 \cdot 8 \\
11 \\
8 \cdot 3 \\
9 \cdot 9 \\
9 \cdot 3 \\
10 \cdot 3 \\
10 \cdot 2\end{array}$ & $\begin{array}{l}1 \\
1 \\
1 \\
0 \\
0 \\
1 \\
0 \\
1 \\
0\end{array}$ & $\begin{array}{c}\text { Inadequate } \\
\text { Inadequate } \\
\text { Adequate } \\
\text { Inadequate } \\
\text { Inadequate } \\
\text { Inadequate } \\
\text { Adequate } \\
\text { Adequate } \\
\text { Inadequate }\end{array}$ \\
\hline \multicolumn{7}{|c|}{ Group $3(n=7)$} \\
\hline $\begin{array}{l}17 \\
18 \\
19 \\
20 \\
21 \\
22 \\
23\end{array}$ & $\begin{array}{l}39(\mathrm{~F}) \\
33(\mathrm{M}) \\
25(\mathrm{~F}) \\
21(\mathrm{~F}) \\
21(\mathrm{M}) \\
24(\mathrm{M}) \\
24(\mathrm{M})\end{array}$ & $\begin{array}{l}22 \cdot 63 \\
25 \cdot 05 \\
26 \cdot 12 \\
23 \cdot 37 \\
26 \cdot 11 \\
20 \cdot 29 \\
21 \cdot 92\end{array}$ & $\begin{array}{r}11 \\
18 \\
16 \\
11 \\
10 \\
8 \\
15\end{array}$ & $\begin{array}{r}8.9 \\
9.8 \\
11.5 \\
9 \cdot 4 \\
9 \cdot 1 \\
7 \cdot 6 \\
8 \cdot 2\end{array}$ & $\begin{array}{l}0 \\
2 \\
0 \\
1 \\
0 \\
0 \\
1\end{array}$ & $\begin{array}{c}\text { Adequate } \\
\text { Inadequate } \\
\text { Adequate } \\
\text { Adequate } \\
\text { Borderline } \\
\text { Adequate } \\
\text { Borderline }\end{array}$ \\
\hline
\end{tabular}

$\star_{0}=$ Normal; $1,2,3=$ mild, moderate, and severe background retinopathy respectively; $4=$ preproliferative retinopathy; $6=$ photocoagulation scars. simple test for the small pupil characteristic of diabetic autonomic neuropathy - that is, diameter of pupil in darkness/diameter of iris (\%). ${ }^{17}$ This may be a reliable test for neuropathy in intermediate length autonomic fibres. ${ }^{13}$

Insulin infusion test for inadequate hypoglycaemic counterregulation - The adequacy of hypoglycaemic counterregulation was tested with a modification of a previously described test. ${ }^{18}$ On the day before the insulin infusion test the diabetic patients took only short acting insulins before each main meal, the last dose being at about $6 \mathrm{pm}$. Patients were maintained in a euglycaemic state (blood glucose concentrations 4.4-6.7 mmol/l) overnight before the test with a previously described insulin infusion method. ${ }^{19}$ The following morning between 830 am and 10 am the infusion was increased to $40 \mathrm{mU} / \mathrm{kg} / \mathrm{h}$. Blood samples were obtained through an indwelling intravenous line at -15 minutes and zero minutes and then at 15 minute intervals for the next 105 minutes of the test, for measurement of glucose and hormone concentrations. On the basis of frequent bedside determinations of plasma glucose concentration and continual observation, glucose counterregulation was categorised as either adequate or inadequate. Inadequate counterregulation was defined by neurological manifestations of hypoglycaemia (seizure, coma, severe lethargy, disorientation, confusion, inappropriate behaviour, or inability to perform simple mathematics ${ }^{18}$ ) or by glucose concentrations that dropped progressively to $<1.9 \mathrm{mmol} / \mathrm{l}$. Adequate counterregulation was defined by the absence of neurological manifestations of hypoglycaemia and by glucose concentrations that either stabilised at $>2.2 \mathrm{mmol} / \mathrm{l}$ or reached a lower level but then rose despite continued insulin infusion. If glucose counterregulation was inadequate the test was terminated. The method described was similar to that of White et al..$^{18}$ Preliminary use of the method, however, had shown that some patients seemed not to have reached the hypoglycaemic crisis for testing counterregulatory adequacy by the end of 105 minutes -that is, the plasma glucose concentration was still $>2 \cdot 2 \mathrm{mmol} / \mathrm{l}$ but falling steadily. Thus the insulin infusion test was continued until either the patient showed inadequate counterregulation according to the above criteria or the fall in plasma glucose concentration seemed to level off, as shown by a fall of $\leqslant 0.2 \mathrm{mmol} / \mathrm{l}$ in 15 minutes. The samples for the 120 minutes before this end point were used for analysing and comparing responses.

Analytical techniques and statistical methods-Plasma glucose concentrations were measured with a glucose oxidase method on a 23 AM glucose analyser (Yellow Springs Instrument Company, Ohio, United States) and plasma pancreatic polypeptide,${ }^{20} \mathrm{C}$ peptide, ${ }^{21}$ and free insulin ${ }^{22}$ concentrations by radioimmunoassay. Statistical analysis was by the unpaired Student's $t$ test, except when otherwise indicated.

\section{Results}

All the diabetic patients showed no response or a negligible $\mathrm{C}$ peptide response to intravenous glucagon.

Insulin infusion test - Seven patients had inadequate hypoglycaemic counterregulation; all of them had neuroglycopenia, and in five the test had to be discontinued before 105 minutes at plasma glucose concentrations $<1.9 \mathrm{mmol} / \mathrm{l}$. Three patients had borderline results, with plasma glucose concentrations levelling off between $1.9 \mathrm{mmol} / \mathrm{l}$ and $2.1 \mathrm{mmol} / 1$ and without neuroglycopenia. The 13 other patients showed adequate counterregulation. Figure 1 shows the glucose responses. The means of the lowest glucose concentrations achieved in each patient were: controls $2.4(\mathrm{SD} 0.36) \mathrm{mmol} / \mathrm{l}$; diabetic patients with adequate 
TABLE II - History of unawareness of hypoglycaemia and results of sweatspot test, pupil test, and seven cardiovascular tests of autonomic function in diabetic patients with inadequate, adequate, and borderline counterregulation

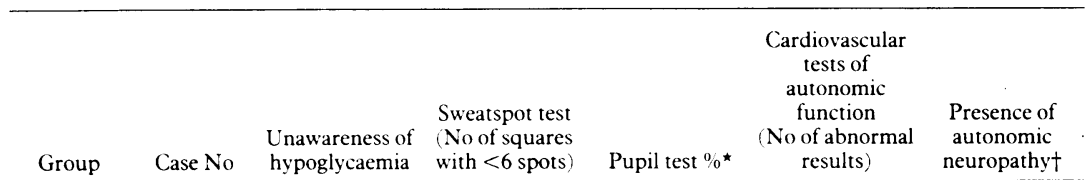

\begin{tabular}{ccccc} 
Group Case No hypoglycaemia & with $<6$ spots $)$ & Pupil test $\%^{\star}$ & $\begin{array}{c}\text { No of abnormal } \\
\text { results })\end{array}$ & $\begin{array}{c}\text { autonomic } \\
\text { neuropathy }\end{array}$ \\
\hline
\end{tabular}

$\begin{array}{ll}2 & \\ 2 & 1 \\ 2 & 1 \\ 2 & 1 \\ 2 & 1 \\ 2 & 1 \\ 3 & 1\end{array}$

$\begin{array}{rrr}8 & + \\ 9 & + \\ 11 & + \\ 12 & + \\ 13 & + \\ 16 & + \\ 18 & +\end{array}$

++
++
++
+
++
+
++
+

$\begin{array}{cl}0 & 55 \cdot 4 \\ 4 & 45 \cdot 95 \\ 1 & 58 \cdot 95 \\ 0 & 48 \cdot 5 \\ 16 \ddagger & 50 \cdot 26 \\ 0 & 59 \cdot 8 \\ 2 & 56 \cdot 4\end{array}$

0
0
0
0
0
0
0

No

No

No

No

Adequate counterregulation

$\begin{aligned} 2 & \\ 3 & - \\ 4 & - \\ 5 & - \\ 6 & - \\ 7 & \\ 10 & + \\ 14 & + \\ 15 & \\ 17 & \\ 19 & - \\ 20 & \\ 22 & \end{aligned}$

$\begin{array}{ll} & \text { Adequel } \\ - & \\ - & \\ - & \\ - & \\ - & \\ + & \\ + & \\ - & \\ + & \\ - & \\ + & \end{array}$

$\begin{array}{cc}60 \ddagger & 32 \cdot 2 \ddagger \\ 60 \ddagger & 30 \cdot 1 \ddagger \\ 58 \ddagger & 52 \cdot 5 \\ 19 \ddagger & 37 \cdot 3 \ddagger \\ 36 \ddagger & 39 \cdot 5 \ddagger \\ 45 \ddagger & 50 \cdot 3 \\ 0 & 60 \cdot 5 \\ 0 & 59 \cdot 8 \\ 0 & 56 \cdot 3 \\ 0 & 56 \cdot 5 \\ 1 & 48 \cdot 2 \\ 0 & 61 \cdot 9 \\ 0 & \text { Not available }\end{array}$

$$
\begin{aligned}
& 6 \neq \\
& 5 \ddagger \\
& 2 \ddagger \\
& 1 \neq \\
& 0 \\
& 3 \ddagger \\
& 0 \\
& 0 \\
& 0 \\
& 1 \\
& 0 \\
& 0 \\
& 0
\end{aligned}
$$$$
\text { No }
$$

Borderline counterregulation

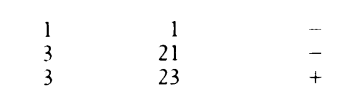

$\begin{array}{cl}21 \neq & 30 \cdot 6 \ddagger \\ 0 & 58 \cdot 0 \\ 0 & 57 \cdot 5\end{array}$

$\begin{array}{cl}4 / 5 \ddagger & \text { Yes } \\ 0 & \text { No } \\ 0 & \text { No }\end{array}$

*Abnormality in pupil test based on age related normal ranges. †Defined as abnormality in two of the three types of test for autonomic neuropathy.

fAbnormal autonomic test results.
++ Often no warning of hypoglycaemia. + Sometimes no warning of hypoglycaemia. -Always warning of hypoglycaemia.

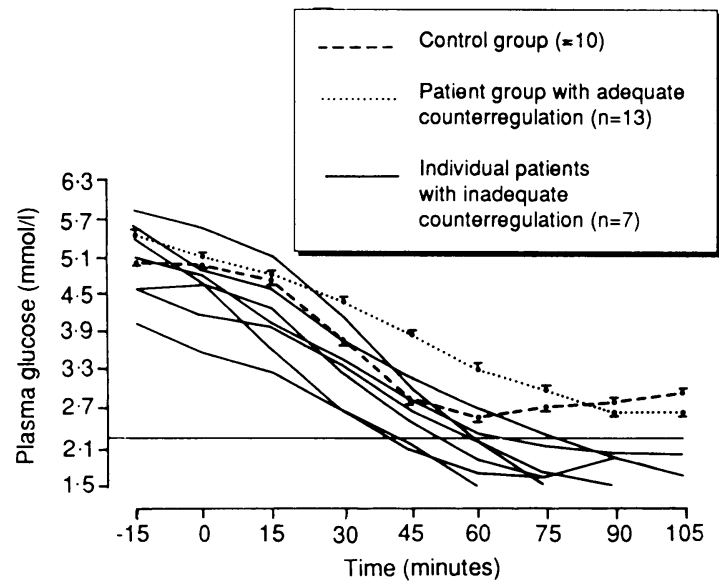

FIG 1-Mean (SE) plasma glucose concentrations during insulin infusion test in control group $(n=10)$, patient group with adequate hypoglycaemic counterregulation $(n=13)$, and individual values in individual patients with inadequate counterregulation $(n=7)$. Horizontal line denotes plasma glucose threshold concentration $(2 \cdot 2 \mathrm{mmol} / \mathrm{l})$ for adequacy of counterregulation hypoglycaemic counterregulation $2 \cdot 56(0 \cdot 26) \mathrm{mmol} / \mathrm{l}$ diabetic patients with inadequate counterregulation $1.63(0 \cdot 18) \mathrm{mmol} / \mathrm{l}$. One of the seven diabetic patients in group 1 had a borderline result, but the rest showed adequate counterregulation (table I). In six of the nine patients in group 2 counterregulation was inadequate whereas in three it was adequate. Of the seven other diabetic patients (group 3), one showed inadequate counterregulation, two borderline counterregulation, and four adequate counterregulation. During the insulin infusion test the plasma concentration of free insulin rose similarly for the diabetic patients with and without adequate counterregulation and the controls and there were no significant differences. Though the mean haemoglobin $A_{1}$ concentration in those with inadequate counterregulation was lower than in those with adequate counterregulation $(9 \cdot 79(0.81) \% v 10 \cdot 49$ $(2 \cdot 41)) \%$, the difference was not significant. Only two patients (cases 1 and 4) had a raised plasma creatinine concentration (in case 1 renal failure was advanced). Four (57\%) of those with inadequate counterregulation and nine $(69 \%)$ with adequate counterregulation showed evidence of diabetic retinopathy (table I). There was no significant difference in the mean duration of diabetes in the patients with inadequate counterregulation and in those with adequate counterregulation $(15.0(4.8) v 14.4(8.2)$ years) or in mean body mass index $(24 \cdot 1(1 \cdot 6) v 23.59$ $\left.(2 \cdot 8) \mathrm{kg} / \mathrm{m}^{2}\right)$.

Autonomic neuropathy-Table II summarises the results of the sweatspot test, pupil test, and cardiovascular tests for the patients with inadequate and adequate hypoglycaemic counterregulation; it gives conclusion for each patient as to the presence of autonomic neuropathy (defined as abnormality in at least two groups of tests). By this assessment none of the patients with inadequate counterregulation but six out of 13 with adequate counterregulation had autonomic neuropathy. Though six out of seven with an abnormal sweatspot test result had adequate counterregulation, only one of the seven patients with inadequate counterregulation had abnormality in this potentially sensitive test for diabetic autonomic neuropathy. The mean duration of diabetes in the patients with autonomic neuropathy was greater than that of the patients without $(18.9(9.0) v 12.7(4.5)$ years), as was mean haemoglobin $\mathrm{A}_{1}$ concentration $(11.57(2.91) v 9.6(1.05) \%)$, though the differences did not achieve significance.

Pancreatic polypeptide concentration could not be measured in the plasma of one patient (case 17) because of a high level of circulating endogenous homologous antibody. Figure 2 shows the responses of plasma pancreatic polypeptide during the insulin infusion test in the controls, and of the diabetic patients with

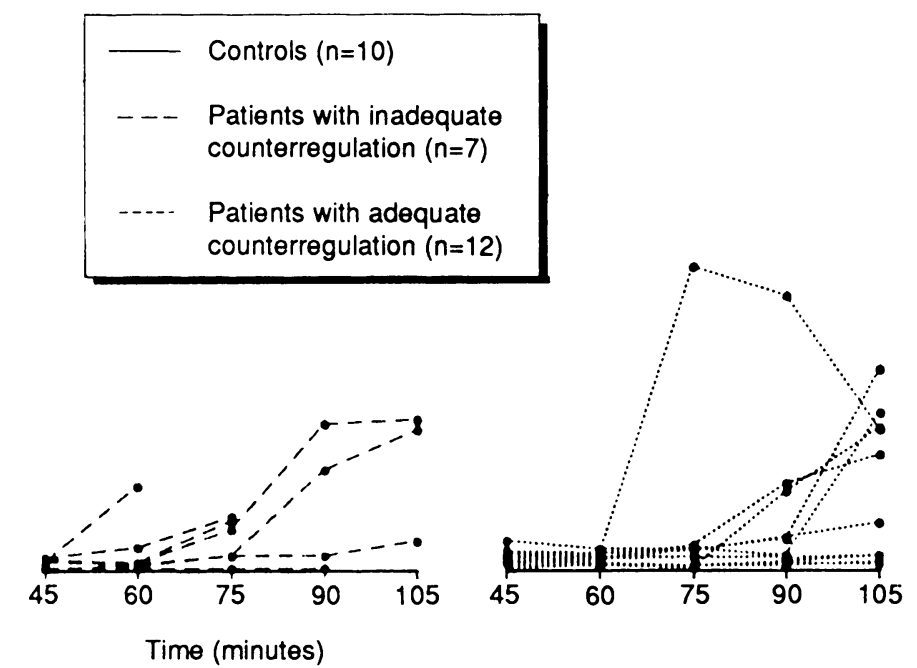

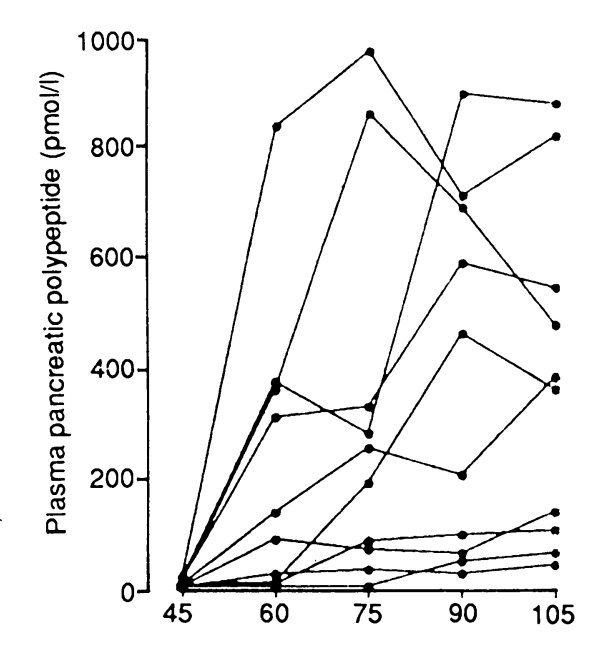

Time (minutes)
FIG 2-Individual responses of plasma pancreatic polypeptide during insulin infusion test (pancreatic polypeptide concentration did not start to rise until after 45 minutes). Curves of six patients with adequate counterregulation who showed little pancreatic polypeptide response cannot be distinguished from each other (bottom curve) 
adequate and inadequate hypoglycaemic counterregulation; it suggests a reduced response for the diabetic patients compared with the controls. Figure 3 compares the change in plasma pancreatic polypeptide concentration of the three groups, where this is the difference between the value at time zero and the maximum value achieved during the test. Nonparametric analysis with the Kruskal-Wallis test indicated a significant difference between the groups $(p<0 \cdot 05)$. The Mann-Whitney $U$ test was used to compare the groups. There was no significant difference between the responses of the pancreatic polypeptide in the diabetic patients with adequate hypoglycaemic counterregulation (median change in plasma pancreatic polypeptide concentration $82 \cdot 1$, range $-22 \cdot 6-505 \cdot 4 \mathrm{pmol} / \mathrm{l}$ ) and those with inadequate counterregulation (median change in plasma pancreatic polypeptide concentration $72 \cdot 4$, range $1 \cdot 8-270 \cdot 8 \mathrm{pmol} / \mathrm{l})$. Both groups had significantly blunted responses compared with the controls (median change in plasma pancreatic polypeptide concentration 414 , range $39-969 \mathrm{pmol} / \mathrm{l}, \mathrm{p}<0.05$ for each group). The lower data points in the group with adequate counterregulation (fig 3) were, however, accounted for by patients with autonomic neuropathy. As a group the patients with autonomic neuropathy (as defined in table II) had a negligible plasma pancreatic polypeptide response (median change in plasma pancreatic polypeptide concentration $3 \cdot 7$, range $-106 \cdot 7-236 \cdot 3 \mathrm{pmol} / \mathrm{l}$, fig 4$)$. The response of plasma pancreatic polypeptide in the patients with adequate counterregulation, but without autonomic neuropathy (median change in plasma pancreatic polypeptide concentration $226 \cdot 8$, range $-22 \cdot 6-505 \cdot 6 \mathrm{pmol} / \mathrm{l}$ ), was not significantly different from that in the normal controls (fig 4). Analysis of the data using parametric tests (one way analysis of variance and unpaired $t$ tests) after logarithmic transformation (because of the skewed nature of the data, fig 3 ) gave essentially similar results.

Unawareness of hypoglycaemia-Five patients said

FIG 3-Change in plasma pancreatic polypeptide concentration during insulin infusion test in controls and patients with adequate and inadequate counterregulation, respectively. Median value in each group depicted by horizontal line

FIG 4-Change in plasma pancreatic polypeptide concentration during insulin infusion test in controls, patients with adequate counterregulation but without autonomic neuropathy, and patients with autonomic neuropathy (includin one with borderline counterregulation). Median value in each group depicted by horizontal line that they often had no warning of hypoglycaemia, seven that they sometimes had no warning, and 11 that they always had warning. None of the seven patients with autonomic neuropathy according to the criteria in table II had a history of unawareness of hypoglycaemia. Out of the 12 patients with a history of unawareness, none had autonomic neuropathy. Table II shows an association between unawareness of hypoglycaemia and inadequate hypoglycaemic counterregulation: all seven $(100 \%)$ patients with inadequate hypoglycaemic counterregulation had unawareness of hypoglycaemia $(++$ or +$)$ compared with five out of $16(31 \%)$ patients with adequate or borderline counterregulation (Fisher's exact test, $\mathrm{p}=0.007$ ).

\section{Discussion}

Inadequate acute glucose counterregulation during hypoglycaemia in insulin dependent diabetes mellitus is accepted as being due to combined deficiency of glucagon and adrenaline secretions. ${ }^{4}$ The aetiology of the deficiency of glucagon secretion is unknown; nevertheless, impaired glucagon secretion during hypoglycaemia is almost universally present after five years' insulin dependent diabetes mellitus, ${ }^{423-25}$ and adequate hypoglycaemic counterregulation is maintained in these patients as long as adequate adrenaline secretion occurs. ${ }^{4}$ Thus the aetiological factor responsible for impairing adrenaline secretion is that which finally decides which patients have inadequate hypoglycaemic counterregulation. Autonomic neuropathy has been considered to be the likely cause..$^{4-7}$

In our study, of the seven patients with considerable autonomic neuropathy, only one had borderline results for inadequate hypoglycaemic counterregulation and the rest had adequate counterregulation. Furthermore, in the seven patients with inadequate counterregulation there was little evidence of autonomic neuropathy. It has previously been suggested that minor, subclinical autonomic neuropathy may be the cause of the hypoglycaemic counterregulatory defect. ${ }^{6}$ There is evidence to suggest that diabetic autonomic neuropathy, like diabetic peripheral neuropathy of the sensory type, is not a patchy neuropathy but a symmetrical polyneuropathy that affects the longest fibres first. ${ }^{2}{ }^{2}$ Therefore abnormalities of sweating in the feet may be present in advance of abnormalities evident in cardiovascular autonomic function tests. ${ }^{326}$ Furthermore, by implication, if diabetic autonomic neuropathy affects the longest fibres first if it is present anywhere in the body it should also be present in the feet. On the basis of this hypothesis, the fact that only one out of seven patients with inadequate hypoglycaemic counterregulation had an abnormal sweatspot test result makes autonomic neuropathy as the cause of the defect unlikely. Though patients with autonomic denervation have diminished adrenaline responses to hypoglycaemia, they also have increased sensitivity to catecholamines. ${ }^{27}$ This may account for the fact that the patients with autonomic neuropathy in our study did not have inadequate hypoglycaemic counterregulation or unawareness of hypoglycaemia.

Though unawareness of hypoglycaemia has been accepted as a textbook feature of diabetic autonomic neuropathy,$^{1-3}$ our data suggest that this is erroneous. Again, on the basis of the hypothesis that if autonomic neuropathy is present anywhere then the sweatspot test result should be abnormal,,$^{13}$ as only one of the 12 patients with unawareness of hypoglycaemia had an abnormal sweatspot test result, subclinical autonomic neuropathy is unlikely to have been the cause. Conversely, none of the patients with advanced autonomic neuropathy on widespread testing had noticed any hypoglycaemic episodes without warning. The results therefore suggest that there is no relation between 
either unawareness of hypoglycaemia or the hypoglycaemic counterregulatory defect and autonomic neuropathy and that these problems have an entirely different aetiology.

Our data may give a clue to the aetiology. In a pertinent review ${ }^{6}$ the major evidence used to conclude that defective adrenergic counterregulation is a manifestation of autonomic neuropathy was a study by White et al. ${ }^{28}$ In that study, during hypoglycaemia, the responses of plasma pancreatic polypeptide and adrenaline were both significantly reduced in the patients with defective hypoglycaemic counterregulation. The authors believed that the plasma pancreatic polypeptide response to hypoglycaemia was a marker of autonomic neuropathy as the cause of the deficient adrenaline response. Our study confirmed a significantly blunted plasma pancreatic polypeptide response in the patients with defective hypoglycaemic counterregulation. This is even more important in that the patients with inadequate counterregulation were rendered considerably more hypoglycaemic than their counterparts with adequate counterregulation and the controls. As these patients with inadequate hypoglycaemic counterregulation do not have appreciable autonomic disease, their blunted plasma pancreatic polypeptide responses are more likely to reflect abnormally diminished autonomic activity during hypoglycaemia rather than actual autonomic neuropathy - that is, the nerves are present but are not being activated.

It may be postulated from studies of animals and humans that there are areas of the brain, perhaps a centre in the hypothalamus, that normally detect hypoglycaemia and trigger activity in the autonomic nervous system. ${ }^{29-31} \mathrm{It}$ is a common clinical observation that certain diabetic patients complain of symptoms of hypoglycaemia with euglycaemic or even hyperglycaemic blood glucose concentrations, and this phenomenon has been reported. ${ }^{32}$ Prolonged hyperglycaemia may cause an upward resetting of the threshold, in such a central glucoregulatory centre, for activating the autonomic nervous system during hypoglycaemia. Similarly, exposure of this centre to frequent hypoglycaemia might cause a downward resetting to explain the hypoglycaemic counterregulatory defect. Recently published studies are in keeping with this hypothesis: Heller et al showed that adrenergic responsiveness and awareness of hypoglycaemia may be diminished during mild hypoglycaemic clamping in some diabetic patients without autonomic neuropathy ${ }^{33}$ and Boyle et al showed an increased glycaemic threshold for symptoms of hypoglycaemia from a mean of $2.9 \mathrm{mmol} / \mathrm{l}$ in normal subjects to a mean of $4.3 \mathrm{mmol} / \mathrm{l}$ in patients with poorly controlled diabetes. ${ }^{34}$ Amiel et al showed an appreciably lower threshold for triggering the release of adrenaline in diabetic patients with a mean haemoglobin $A_{1}$ concentration of $7 \cdot 6 \%$ compared with those with a mean concentration of $11 \cdot 5 \%$. Particularly importantly, they showed that reducing haemoglobin $A_{1}$ concentration with intensive treatment in some of their patients with poorly controlled diabetes resulted in a lowering of the threshold for adrenaline release. Though in our study the lower haemoglobin $A_{1}$ concentration in the group of patients with inadequate hypoglycaemic counterregulation did not achieve significance, the data are nevertheless in keeping with a hypothetical glucoregulatory centre, perhaps in the hypothalamus, which is failing to sense hypoglycaemia in the patients with defective counterregulation and therefore failing to trigger release of adrenaline and pancreatic polypeptide via the sympathetic and parasympathetic nervous systems.

We thank Dr $\mathbf{R}$ Newcombe, department of medical statistics and computing, University of Wales College of
Medicine, for help with the statistical analysis, and Sisters $\mathrm{H}$ Smith and M Abouharb, diabetic research unit, University of Wales College of Medicine, for help during the insulin infusion studies.

1 Alberti KGMM, Hockaday TDR. Diabetes mellitus. In: Weatherall DJ, Ledingham JGG, Warrell DA, eds. Oxford textbook of medicine. Vol 1 . Oxford: Oxford University Press, 1983:9.5-9.49.

2 Thomas PK, Eliasson SG. Diabetic neuropathy. In: Dyck PJ, Thomas PK, Lambert SH, Burge R, eds. Peripheral neuropathy. Vol II. London: Saunders, 1984:1173-810.

3 Ewing DJ, Clarke BF. Autonomic neuropathy: its diagnosis and prognosis. Clinics in Endocrinology and Metabolism 1986;15:855-88.

4 Cryer PE, Gerich JE. Glucose counterregulation, hypoglycemia and the intensive therapy of diabetes mellitus. N Engl f Med 1985;313:232-41.

5 Wilson DE. Excessive insulin therapy: biochemical effects and clinica repercussions. Current concepts of counterregulation in Type I diabetes. Ann Intern Med 1983;98:219-27.

6 Cryer PE. The metabolic impact of autonomic neuropathy in insulin dependent diabetes mellitus. Ann Intern Med 1986;146:2127-9.

7 Cryer PE, Gerich JE. Relevance of glucose counterregulatory systems to patients with diabetes: critical roles of glucagon and epinephrine. Diabetes Care 1983;6:95-9.

8 Kleinbaum K, Shamoon H. Impaired counterregulation of hypoglycemia in insulin dependent diabetes mellitus. Diabetes 1983;32:493-8.

9 Hoeldtke RD, Boden G, Shuman CR, Owen OE. Reduced epinephrine secretion and hypoglycemia unawareness in diabetic autonomic neuropathy. Ann Intern Med 1982;96:459-62.

10 Ryder REJ, Vora JP, Atiea JA, Owens DR, Hayes TM, Young SA. Possible new method to improve detection of diabetic retinopathy - polaroid nonmydriatic retinal photography. $\mathrm{Br}$ Med $\mathcal{F}$ 1985;291:1256-7.

11 Faber OK, Binder C. C-peptide response to glucagon. Diabetes 1977;26: 605-10

12 Thomas PK. Metabolic neuropathy. I R Coll Physicians Lond 1973;7:154-60.

13 Ryder REJ, Marshall R, Johnson K, Ryder AP, Owens DR, Hayes TM Acetylcholine sweatspot test for autonomic denervation. Lancet 1988; 1303-5.

14 Ewing DJ, Clarke BF. Diagnosis and management of diabetic autonomic neuropathy. $\mathrm{Br}$ Med $\mathcal{F}$ 1982;285:916-8.

15 Ewing DJ, Borsey DQ, Bellavere F, Clarke BF. Cardiac autonomic neuropathy in diabetes: comparison of measures of $R-R$ interval variation. Diabetologia 1981;21:18-24.

16 Sundkvist G, Lilja B, Almer LO. Abnormal diastolic blood pressure and hear rate reactions to tilting in diabetes mellitus. Diabetologia 1980;19:433-8.

17 Smith SA, Dewhirst RR. A simple diagnostic test for pupillary abnormality in diabetic autonomic neuropathy. Diabetic Med 1986;3:38-41.

18 White NH, Skor DA, Cryer PE, Levandoski LA, Bier DM, Santiago JV. Identification of Type I diabetic patients at increased risk for hypoglycemia during intensive therapy. $N$ Engl f Med 1983;308:485-91.

19 White NH, Skor D, Santiago JV. Practical closed loop insulin delivery: system for maintenance of overnight euglycemia and the calculation of basa insulin requirements in insulin-dependent diabetics. Ann Intern Med 1982;97: 210-3.

20 Adrian TE. Pancreatic polypeptide. In: Bloom SR, Long RG, eds. Radio immunoassay of gut regulatory peptides. London: Saunders, 1982:92-5.

21 Heding LG. Radioimmunological determination of human C-peptide in serum. Diabetologia 1975;8:541-8.

22 Owens DR. Human insulin: clinical pharmacological studies in normal man. Lancaster: MTP Press, 1986:127-34.

23 Bolli G, DeFeo P, Compagnucci P, et al. Abnormal glucose counterregulation in insulin-dependent diabetes mellitus. Interaction of anti-insulin antibodies and impaired glucagon and impaired glucagon and epinephrine secretion. Diabetes 1983;32:134-41.

24 Polonsky KS, Herold KC, Gilden JL, et al. Glucose counterregulation in patients after pancreatectomy: comparison with other clinical forms of diabetes. Diabetes 1984;33:1112-9.

25 Campbell LV, Krangen EW, Lazarus L. Defective blood glucose counterregulation in diabetes is a selective form of autonomic neuropathy. $\mathrm{Br} \mathrm{Med} \mathcal{f}$ 1977;ii: 1527-9.

26 Ewing DJ, Clarke BF. Diabetic autonomic neuropathy: present insights an future prospects. Diabetes Care 1986;9:648-65.

27 Hilsted J, Madsbad S, Krarup T, Christensen NJ, Tronier B, Galbo H. Hormonal, metabolic, and cardiovascular response to hypoglycemia in diabetic autonomic neuropathy. Diabetes 1981;30:626-33.

28 White NH, Gingerich RL, Levandoski LA, Cryer PE, Santiago JV. Plasm pancreatic polypeptide response to insulin induced hypoglycemia as a marker for defective glucose counterregulation in insulin dependent diabetes mellitus. Diabetes 1985; 34:870-5.

29 Himsworth RL. Hypothalamic control of adrenaline secretion in response to insufficient glucose. F Physiol (Lond) 1970;206:411-7.

30 Frizzell RT, Biggers DW, Myers SR, Jaspan JB, Williams PE. Role of different regions of the brain in directing hormone release and glucose production during insulin induced hypoglycemia. Diabetes 1988;37(supp 1):71A.

31 Boden G, Reichard GA, Hoeldtke RD, Rezvani L, Owen OE. Severe insulin induced hypoglycemia associated with deficiencies in the release of counterregulatory hormones. $N$ Engl f Med 1981;305:1200-4.

32 De Fronzo RA, Hendler R, Christensen N. Stimulation of counterregulatory hormonal responses in diabetic man by a fall in glucose concentration. Diabetes 1980;29:125-31.

33 Heller SR, Macdonald IA, Herbert M, Tattersall RB. Influence of sympathetic nervous system on hypoglycaemic warning symptoms. Lancet 1987;ii: 359-63.

34 Boyle PJ, Schwartz NS, Shah SD, Clutter WE, Cryer PE. Plasma glucose concentrations at the onset of hypoglycemic symptoms in patients with poorly controlled diabetes and in nondiabetics. $N$ Engl f Med 1988;318: 1487-92.

35 Amiel SA, Tamborlane WV, Simonson DC, Sherwin RS. Defective glucose counterregulation after strict glycemia control of insulin-dependent diabetes mellitus. N Engl f Med 1987;316:1376-83.

(Accepted 16 fune 1990) 